\title{
Estimation of radiation non-regulatory stochastic risks for meadow plants of the semipalatinsk test site
}

\author{
V.L. Tetenkin ${ }^{1}$, S.I. Spiridonov ${ }^{1}$, M.K. Mukusheva ${ }^{2}$ and E.I. Karpenko ${ }^{1}$ \\ ${ }^{1}$ Russian Institute of Agricultural Radiology and Agroecology, 249032 Obninsk, Russia \\ ${ }^{2}$ National Nuclear Center of Kazakhstan, 071100 Kurchatov, Kazakhstan
}

\begin{abstract}
An algorithm and formulas to estimate non-regulatory stochastic risks (for biota and humans) have been derived. These were used to assess radiation risks for meadow plants within the Semipalatinsk Test Site (STS). It has been shown that on small plots with relatively high radiation levels $(\sim 0.25 \mathrm{mGy} / \mathrm{h})$ the radiation risks of death of radiosensitive plants (leguminous and coniferous shrubs) have a noticeable value $(>2 \%)$. In the other STS area, radiation is not a danger to the vegetation.
\end{abstract}

\section{INTRODUCTION}

Over 1949-1989, at the Semipalatinsk Test Site (STS) 456 nuclear weapons tests were carried out resulting in a release to the environment of large amounts of long-lived radionuclides, including some $9 \cdot 10^{16} \mathrm{~Bq}{ }^{137} \mathrm{Cs}$, which is comparable with the amount of this radionuclide released after the Chernobyl accident [3]. A study into the radiation effects on the unique meadow vegetation of Kazakhstan is of great interest, since exactly this natural component that is responsible for the formation of cenosis over the whole STS area.

Radiation effects in plant populations are characterized by large uncertainty, due to the influence of many factors. In estimations of radiation effects, it is reasonable to make use of ecological risks as the integrated indices. These describe a probability of unfavorable outcome under the action for some time of a stressor [1, 2].

In general, both the acting factor and extent of a biological effect are random variables, which are described by density distributions (probability density). In this case, Risk is integral of distribution overlapping, which can be estimated without any assumptions of the limit values of the indices used. This provides a way to overcome uncertainty and subjectivity typical for estimations based on standard indices.

Hence, for stochastic risk computation the following components are necessary:

- distribution (form and parameters) of the acting factor (dose rate);

- distribution (form and parameters) of the value for biological effect as a function of dose rate;

- formula (relating these density distributions) for risk computation.

In the present paper, death rate of plants is taken as a biological effect criterion, since it is the most evident integral indicator of the radiation factor effects on biota.

\section{MATERIALS AND METHODS}

As STS sites for radiation risk assessment to meadow plants, pastures were considered located near the wintering ground «Atomic Lake» and a site with high radioactive contamination in close vicinity to Abnormal Pithole 1069 (site «Balapan»). The data on the content of the main dose-forming radionuclides in the soil of pastures near the «Atomic Lake» used to compute dose burdens were submitted by the National Nuclear Center (Kazakhstan). 
The radioactive contamination data for the site near Abnormal Pithole 1069 were taken from [3] using some data from [4] for reconstruction of ${ }^{60} \mathrm{Co},{ }^{152} \mathrm{Eu}$ and ${ }^{154} \mathrm{Eu}$ concentrations. Dose burdens to meadow plants were estimated with a dosimetric model devised on the basis of the multilayer model for aquatic ecosystems [5].

The information on plant radioresistance was taken from [6-8] using some data from the International radiation database Frederica-online.org.

All data were transformed to the same criterion: $L D_{50}$ for 6 years of chronic exposure. To this end, transfer factors cited in [9] were used. Arbitrary $L D_{50}$ values for the different living forms of the same plant group (family) where estimated as follows:

\begin{tabular}{|c|c|c|c|}
\hline $\begin{array}{c}\text { Living } \\
\text { Form }\end{array}$ & $\begin{array}{c}\text { Annual herbs } \\
\text { (one season) }\end{array}$ & $\begin{array}{c}\text { Perennial herbs } \\
\text { (6 years) }\end{array}$ & $\begin{array}{c}\text { Shrubs \& shrub-like plants } \\
\text { (6 years) }\end{array}$ \\
\hline$L D_{50}$ & 100 & $\sim 25$ & $\sim 16$ \\
\hline
\end{tabular}

All distributions, including $L D_{50}$ distributions at the family levels, were described by the Gammadistribution function, its probability density being expressed as follows:

$$
P(\alpha, m, x)=\frac{\alpha}{m \Gamma(\alpha)}\left(x \frac{\alpha}{m}\right)^{\alpha-1} \exp \left(-x \frac{\alpha}{m}\right)
$$

where $m$ is the mean value of a random variable, $\alpha$ is the shape parameter: $\alpha=m^{2} / \mathrm{s}^{2}$ (s is the standard deviation), $\Gamma(\alpha)$ is the normalizing coefficient (Euler gamma-function), $x$ is the variable (dose rate).

Plant death rate was taken as a parameter defining radioresistance of plant populations. Dependences of this parameter $\boldsymbol{F}(\boldsymbol{D})$ on dose rate were reconstructed using (1) probability densities of plant group $L D_{50}$ and (2) mortality dependence on dose rate of naturally growing species. Considering that all species have near the same shape of dose-effect dependence, the following formula is correct:

$$
\boldsymbol{F}(\boldsymbol{D})=\int_{0}^{\infty} P(\alpha, m, X) \cdot F(2.24, X \cdot 1.1685, D) d X
$$

where $\boldsymbol{F}(\boldsymbol{D})$ is the plant group distribution function of mortality-dose rate dependence; $\boldsymbol{P}(\alpha, m, \boldsymbol{X})$ is the probability density value of $L D_{50}$ at point $\boldsymbol{X}$ of dose rate ( $\alpha$ and $m$ are the parameters of Gammadistribution); $\boldsymbol{F}\left(\alpha_{0}, m_{0}, \boldsymbol{D}\right)$ is the species distribution function value at point $\boldsymbol{D}$ of dose rate $\left(\alpha_{0}\right.$ and $m_{0}$ are the parameters of Gamma-distribution; after data analysis constant $\alpha_{0}=2.24 ; m_{0}$ is the variable mean value of Gamma-distribution; integration variable $\boldsymbol{X}$ corresponds to median of distribution, and coefficient 1.1685 transforms $\boldsymbol{X}$ to the mean value $m_{0}$ ).

Probabilistic description of spatial heterogeneity of dose burdens to plants growing in the study area was also based on Gamma-distributions.

The mathematical parameters of distributions were optimized by the simplex-method based on the minimum of residual variance. For the optimization procedure the cumulative histograms of experimental data (without any grouping) where used and these were mathematically described by Gamma-distribution functions (or by a sum of such two functions).

Mathematical processing and computations used the «MATLAB » software (The MathWorks, Inc., 21 Eliot St., South Natick, MA 01760).

\section{RESULTS AND DISCUSSION}

\subsection{Parameters of distributions of dose rates and mortality of plants}

The unique STS flora contains some 200 plant species. However, no data are available on the radioresistance of these species. Therefore, the radioresistance analysis was made at the level of groups 
(families) of plants assuming approximately the same radioresistance heterogeneity for plant families from different regions of the Earth. The floristic analysis has revealed that within the experimental sites most common are perennial herbaceous families Poaceae and Asteraceae. These have practically the same radioresistance parameters and were analyzed collectively. The most radiosensitive meadow plants within the study sites are coniferous and leguminous shrubs (Ephedra distachia, Ephedraceae, and Caragana pumila, Fabaceae). Spatial heterogeneity of radioactive contamination of pastures and radioresistance (mortality) of plant groups are described as superposition of two Gamma-distributions: $P=P_{1} \cdot \mathrm{C}_{1}+\mathrm{P}_{2} \cdot \mathrm{C}_{2}$ (corresponding average $\mathrm{m}=\mathrm{m}_{1} \cdot \mathrm{C}_{1}+\mathrm{m}_{2} \cdot \mathrm{C}_{2}$ ). The distribution parameters are presented in Table 1 . The corresponding probability densities (or distribution functions) are shown in Figs. 1 and 2.

Table 1. Parameters of Gamma-distributions for experimental data of objects used for stochastic Risks determination.

\begin{tabular}{|l||c|c|c||c|c|c||c|}
\hline \multicolumn{1}{|c||}{ Parameter } & \multicolumn{3}{c||}{$\begin{array}{c}\text { Low dose part of } \\
\text { distribution }\end{array}$} & \multicolumn{3}{c|}{$\begin{array}{c}\text { High dose part of } \\
\text { distribution }\end{array}$} & Average \\
\cline { 2 - 9 } & $\mathbf{m}_{\mathbf{1}}$ & $\boldsymbol{\alpha}_{\mathbf{1}}$ & $\mathbf{C}_{\mathbf{1}}$ & $\mathbf{m}_{\mathbf{2}}$ & $\boldsymbol{\alpha}_{\mathbf{2}}$ & $\mathbf{C}_{\mathbf{2}}$ & $\mathbf{m}$ \\
\hline \multirow{2}{*}{ Object } & 250 & 2.60 & 100 & - & - & - & 250 \\
\hline $\begin{array}{l}\text { Dose rate near } \\
\text { Abnormal Pithole 1069 }\end{array}$ & 0.12 & 0.72 & 97.8 & 2.69 & 1.58 & 2.2 & 1.74 \\
\hline $\begin{array}{l}\text { DR on Pastures around } \\
\text { «Atomic Lake» }\end{array}$ & 1000 & 1.84 & 44 & 2640 & 1.77 & 56 & 1920 \\
\hline $\begin{array}{l}\text { Fabaceae shrubs mortality } \\
\text { (Caragana pumila) }\end{array}$ & 1190 & 2.16 & 47 & 2370 & 2.15 & 53 & 1810 \\
\hline $\begin{array}{l}\text { Coniferaceae shrubs mortality } \\
\text { Ephedra distachia) }\end{array}$ & 9090 & 1.55 & 44 & 26920 & 1.50 & 56 & 19070 \\
\hline $\begin{array}{l}\text { Poaceae \& Asteraceae } \\
\text { perennial herbs mortality }\end{array}$ & & & & & & & $\boldsymbol{\mu} \mathbf{G y / h}$ \\
\hline
\end{tabular}

\subsection{Equations for the stochastic Risk calculation}

At point $X$ (Fig. 1 insertion) the probability of dose rate $\mathrm{W}_{1}(X)=\mathrm{P}_{1}(X) d X$, and corresponding semistochastic Risk (probability of plant death) is the left part of radioresistance distribution $(D \leq X)$ :

$$
\mathrm{W}_{2}(X)=\int_{0}^{X} P_{2}(D) d D
$$

Because of the independence of the stochastic variables used, a subsequent differential Risk value is the production of the corresponding probabilities ( $\boldsymbol{I}$ is the non-normalized probability density of $\boldsymbol{R i s k s}$ ):

$$
d \boldsymbol{R i s k}_{1}(X)=\boldsymbol{I}_{1}(X) d X=\mathrm{W}_{2}(X) \cdot \mathrm{W}_{1}(X)=\mathrm{W}_{2}(X) \cdot P_{1}(X) d X
$$

Alternatively, the probability of plant mortality at point $X$ is $\mathrm{W}_{2}(X)=\mathrm{P}_{2}(X) d X$; corresponding semistochastic Risk is the right part of dose rate distribution $(D R>X)$, and subsequent



The more obvious presentation of differential form of Risk is complete overlapping of factor and object distributions as a Sum of partial overlapping functions $\boldsymbol{I}_{1}$ and $\boldsymbol{I}_{2}: \boldsymbol{I}=\boldsymbol{I}_{1}+\boldsymbol{I}_{2}$. This variable smoothly fills all space between the $P_{1}$ and $P_{2}$ density functions (Fig. 1 insertion). 
Risk value is an integral of either $\boldsymbol{I}_{1}$, or $\boldsymbol{I}_{2}$ (or of the complete $\boldsymbol{I}$ function with coefficient $1 / 2$ ):

$$
\text { Risk }=\int_{0}^{\infty} P_{1}(X)\left[\int_{0}^{X} P_{2}(D) d D\right] d X=\int_{0}^{\infty} P_{2}(X)\left[\int_{X}^{\infty} P_{1}(D) d D\right] d X=\frac{1}{2} \int_{0}^{\infty} I(X) d X
$$

The derived expressions have several simple consequences. Let $\mathrm{M}_{1}$ be a mean value of $D R, \mathrm{M}_{2}$ is the mean value of plant radioresistance, $S_{1}$ and $S_{2}$ are the corresponding standard deviations.

1. $\left|\left(M_{2}-M_{1}\right)\right| \gg S_{1}+S_{2}$ (distributions of dose rate and radioresistance are located in different dose domains and are not overlapped):

Risk $\approx 0\left(\mathrm{M}_{2}>\mathrm{M}_{1}-\right.$ usual case $)$ or

Risk $\approx 1\left(\mathrm{M}_{2}<\mathrm{M}_{1}-\right.$ verydangerous case $)$.

2. $\mathrm{S}_{1} \ll \mathrm{S}_{2}$ or $\mathrm{S}_{1} \gg \mathrm{S}_{2}$, the cases of usual semistochastic Risks:

$$
\text { Risk }=\int_{0}^{M_{1}} P_{2}(D) d D, \text { or } \boldsymbol{R i s k}=\int_{M_{2}}^{\infty} P_{1}(D) d D
$$

3). $\mathrm{M}_{2} \approx \mathrm{M}_{1}$ and $\mathrm{S}_{1} \approx \mathrm{S}_{2}$ (distributions of dose rate and radioresistance coincide):

Risk $\approx 1 / 2=50 \%$.

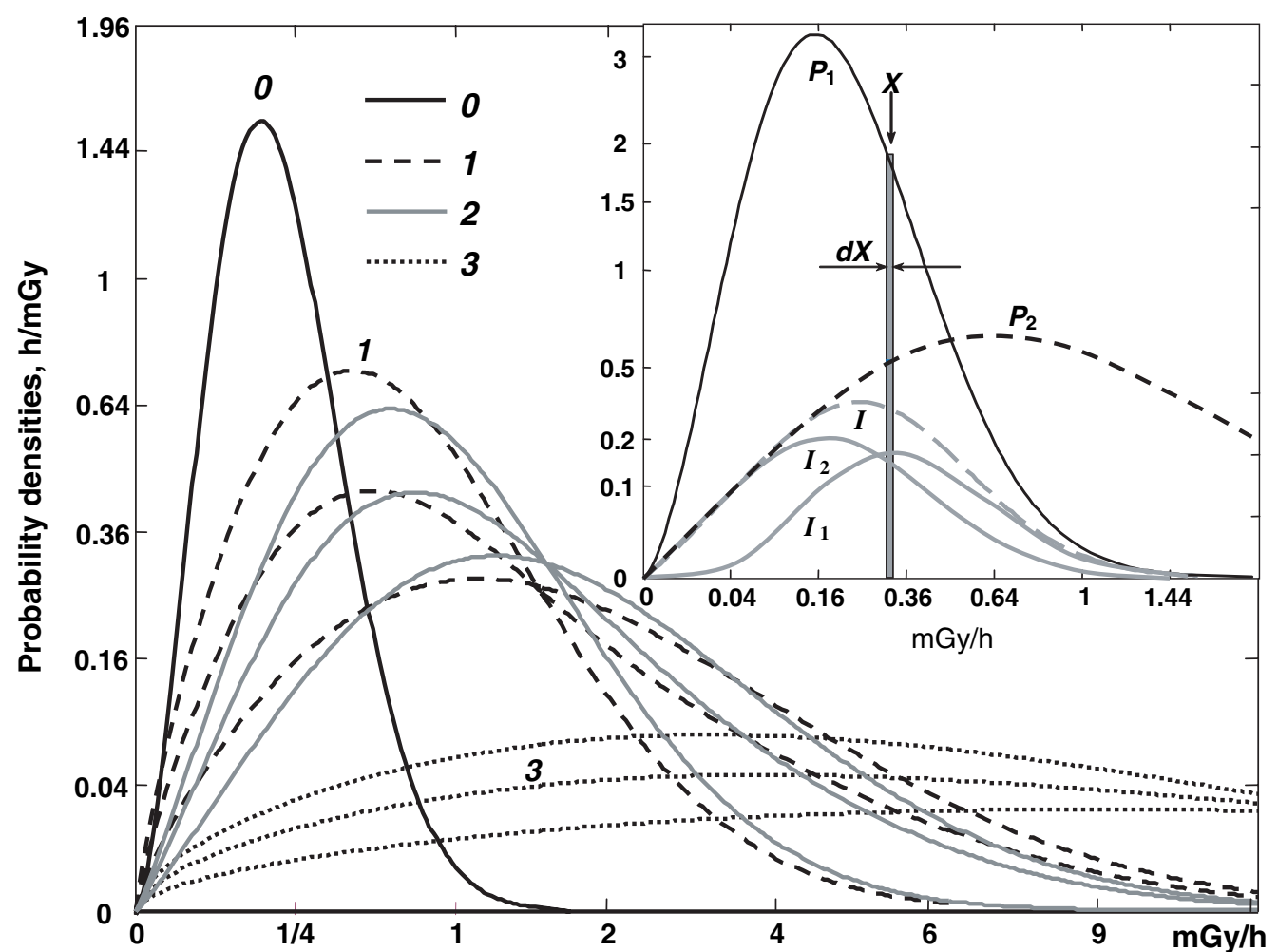

Figure 1. Probability densities of dose rate distribution near the Abnormal Pithole 1069 and radioresistance (mortality) of some meadow plants (for the best visualization both scales are nonlinear and proportional to square roots of corresponding values). Probability densities of mortality are shown for the mean values (middle curves), for the low dose part (upper left at $\max ; \mathrm{C}_{1}=100 \%$ ) and for the high dose part of resistance (lower right at $\max$; $\mathrm{C}_{2}=100 \%$ ). Parameters of low dose and high dose parts are presented in Table 1.0 - two fold diminished dose rate distribution $\left(P_{1} / 2\right) ; 1$ - leguminous shrubs; 2 - coniferous shrubs; 3 - common meadow perennial grasses (Poaceae \& Asteraceae); Insertion: probability densities of dose rate distribution $\left(P_{1}\right)$, mortality of leguminous shrubs $\left(P_{2}\right)$ and distribution overlapping $\left(\boldsymbol{I}_{1}, \boldsymbol{I}_{2}\right.$ and $\left.\boldsymbol{I}=\boldsymbol{I}_{1}+\boldsymbol{I}_{2}\right)$. 


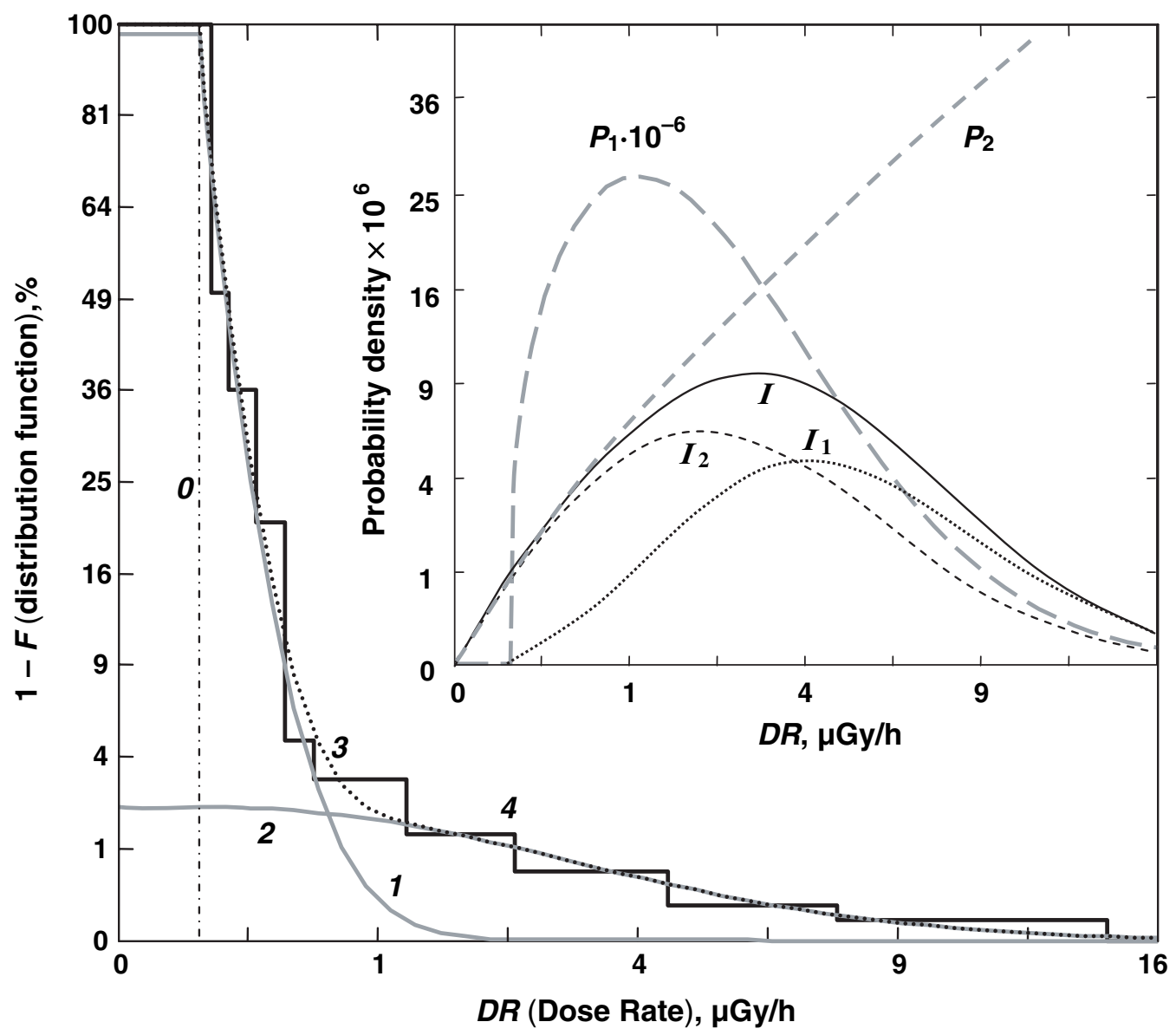

Figure 2. Spatial distribution of radioactivity on STS meadow pastures around «Atomic Lake» (for the best visualization both scales are nonlinear and proportional to square roots of corresponding values). 0 - background $D R$ value $(0.1 \mu \mathrm{Gy} / \mathrm{h}) ; 1,2$ - calculated components of $D R$ distribution; 3 - sum of components 1 and 2; 4 - experimental cumulative histogram of radiation distribution. Parameters of calculated components (over the background value of radiation) are given on Table 1. Insertion: probability densities of dose rate distribution $\left(P_{1}\right)$ of component 2, mortality of leguminous shrubs $\left(P_{2}\right)$ and distribution overlapping $\left(\boldsymbol{I}_{\mathbf{1}}, \boldsymbol{I}_{\mathbf{2}}\right.$ and $\left.\boldsymbol{I}=\boldsymbol{I}_{\mathbf{1}}+\boldsymbol{I}_{\mathbf{2}}\right)$.

\subsection{Assessment of radiation risk for meadow STS vegetation}

Using Eq. (5) and mathematical descriptions of density distributions of radioactivity and radioresistance (Table 1), radiation risks for some STS meadow plants have been estimated. Results of Risk estimation are summarized in Table 2.

The Min, Mean and Max risk values belong to the high dose part, mean values and low dose part of plant group radioresistance, respectively (Table 1, Fig. 1).

As is evident from the table 2, the risk values for meadow plants of pastures are negligible, less than $10^{-5}$ (the derived values are actually beyond the probable accuracy limits, about $10^{-3}$, of the method for assessment of stochastic risks described in this paper). On pastures in the vicinity of «Ground Zero » radioactive contamination and, consequently, risk values are much less (data are not presented). 
Table 2. Stochastic Risks of plant mortality for different STS areas.

\begin{tabular}{|c|c|c|c|c|}
\hline \multirow[b]{2}{*}{ Territory } & \multirow[b]{2}{*}{ Plant group } & \multicolumn{3}{|c|}{ Risk values } \\
\hline & & Min & Mean & $\operatorname{Max}$ \\
\hline \multirow{3}{*}{$\begin{array}{l}\text { Pastures around } \\
\text { «Atomic Lake» } \\
(\mathrm{STS}, \ll \text { Balapan })\end{array}$} & Fabaceae shrubs & $3.8 \cdot 10^{-7}$ & $8.8 \cdot 10^{-7}$ & $15.2 \cdot 10^{-7}$ \\
\hline & Coniferaceae shrubs & $0.5 \cdot 10^{-7}$ & $1.2 \cdot 10^{-7}$ & $2.1 \cdot 10^{-7}$ \\
\hline & Perennial herbs & $0.7 \cdot 10^{-7}$ & $1.5 \cdot 10^{-7}$ & $2.5 \cdot 10^{-7}$ \\
\hline \multirow{3}{*}{$\begin{array}{l}\text { Dirty part of } \\
\text { Pastures around } \\
\text { «Atomic Lake» }\end{array}$} & Fabaceae shrubs & $1.2 \cdot 10^{-5}$ & $2.9 \cdot 10^{-5}$ & $5.2 \cdot 10^{-5}$ \\
\hline & Coniferaceae shrubs & $2.0 \cdot 10^{-6}$ & $5.0 \cdot 10^{-6}$ & $8.5 \cdot 10^{-6}$ \\
\hline & Perennial herbs & $1.7 \cdot 10^{-6}$ & $3.7 \cdot 10^{-6}$ & $6.3 \cdot 10^{-6}$ \\
\hline \multirow{3}{*}{$\begin{array}{l}\text { Abnormal Pithole } \\
(\text { Slit) } 1069 \\
(« \text { Balapan })\end{array}$} & Fabaceae shrubs & $2.7 \%$ & $6.5 \%$ & $11.3 \%$ \\
\hline & Coniferaceae shrubs & $2.0 \%$ & $4.4 \%$ & $7.0 \%$ \\
\hline & Perennial herbs & $0.1 \%$ & $0.3 \%$ & $0.6 \%$ \\
\hline
\end{tabular}

The site with relatively high level of radioactive contamination in close vicinity to Abnormal Pithole 1069 («Balapan») is a small spot, only about $30 \mathrm{~m}$ in diameter. Such spots probably exist near the epicenters of surface bursts within the STS experimental site « Ground Zero ».

As is seen from the table, on spots with relatively high radiation levels, there is noticeable death hazard (more than 2\%) for radiosensitive plant groups. In these conditions radiosensitive plants cannot possibly propagate by seeds, since seed production is much more sensitive to radiation than plant vitality [4].

It should be noted that dose rate value within these spots $(\sim 0.25 \mathrm{mGy} / \mathrm{h})$ is lower than the permissible level of dose rate $(\sim 0.40 \mathrm{~m} \mathrm{~Gy} / \mathrm{h})$ recommended for terrestrial plants [10]. This standard seems to be overestimated and needs to be revised.

On the other hand, the Risk values for vegetation on pastures are neglected, even in the most affected part of the area. Evidently, radiation risks for vegetation are lacking on pastures, which is in agreement with the results of investigations into the composition of meadow phytocenoses.

\section{References}

[1] Covello V.T. and Merkhofer M.W. Risk Assessment Methods. Plenum Press, New York and London (1993)

[2] EPA/630/R-95/002F in: Risk Assessment Forum, U.S. Environmental Protection Agency, Washington DC, Federal Register, 63, 26846-26924 (1998)

[3] USSR nuclear weapons tests: the modern radioecological state of the test sites. Authors' team headed by Prof. V.A. Logachev, Moscow, IzdAT (2002)

[4] Artem'ev, O.I., Umarov, M.A., Larin, V.N. and Protsky, A.V. Messeger NNC RK (in Russian), No 3, 24-29 (2002)

[5] Fesenko, S.V. Influence of Radiation Factor on Fresh-water ecosystem. Autoref. of Dissertation (In Russian), Moscow, MIFI (1985)

[6] Davies, C.R., Radiation Botany 13, 127-136 (1973)

[7] Dugle, J.R. and Mayoh, K.R., Environmental and Experimental Botany, 24, 267-276 (1984)

[8] Grodzinsky, D.M. Plant Radiobiology (in Russian), Kiev, Naukova Dumka (1993).

[9] Framework for Assessment of Environmental Impact Eds. Dennis Woodhead, CEFAS, and Irene Zinger, EA, A project within the EC 5th Framework Programme, FASSET 2, Contract No FIGECT-2000-00102 (2003)

[10] DOE Standard. A Graded Approach for Evaluation Radiation Doses to Aquatic and Terrestrial Biota. Washington: US Department of Energy, D.C. 20585, Project number ENVR-0011, US Department of Energy (2000) 